\title{
Editorial: Geoscience Communication - Building bridges, not walls
}

\author{
Sam Illingworth ${ }^{1}$, Iain Stewart ${ }^{2}$, Jonathan Tennant ${ }^{3}$, and Kirsten von Elverfeldt ${ }^{4}$ \\ ${ }^{1}$ School of Science and the Environment, Manchester Metropolitan University, Manchester, UK \\ ${ }^{2}$ School of Geography, Earth and Environmental Sciences, Plymouth University, Plymouth, UK \\ ${ }^{3}$ Open Science MOOC; paleorXiv, UK \\ ${ }^{4}$ Department of Geography and Regional Studies, Alpen-Adria-Universität Klagenfurt, Klagenfurt, Austria
}

Correspondence: Sam Illingworth (s.illingworth@mmu.ac.uk)

Published: 11 June 2018

\section{Geoscience Communication - why bother?}

Welcome to the journal of Geoscience Communication! Since launching in April 2018, we have had dozens of great inquiries, many of which have been along the lines of "So what is the Geoscience Communication $(G C)$ journal all about?" As such, we decided to write this editorial in order to introduce ourselves (the executive editors of $G C$ ), to provide a history of its development, and to serve as a guideline for future authors who wish to submit to this journal. We hope that this article serves as a useful aid for people who are considering publishing in $G C$, as well as the wider geoscience community, and that it can act in the first instance as an FAQ for authors, editors, and readers alike.

As executive editors we are responsible for helping to ensure the credibility of the journal, and for providing assistance to editors, reviewers, and authors during the peer review process. The most important thing that we need to stress here is that we are all human beings, and that if you have any questions please just reach out to us by using the email address gc-executiveeditors@mailinglists.copernicus.org, which gets sent to all of us. One of us will try to get back to you within $48 \mathrm{~h}$, and we are always happy to hear any suggestions or improvements that you might have for the journal.

But who are we? Sam is a Senior Lecturer in Science Communication at Manchester Metropolitan University in the UK, where his research involves the development of dialogue between scientists and non-scientists, facilitating this through the use of poetry and games. Kirsten is an Associate Professor in Geography with an interest in the selforganisation that occurs in natural systems, and the chal- lenges that we face in communicating risk. Iain is Professor of Geoscience Communication at the University of Plymouth and works with media production companies making popular science television documentaries. Jon is a palaeontologist and "rogue researcher", currently working on a range of projects related to either dinosaurs or scholarly communication, including primary research, publishing consultancy, and the development of an Open Science Massive Open Online Course (MOOC).

This journal follows on from several years of market research, feasibility studies, and discussions within and across the global geoscience community. Following several of these discussions, particularly at the European Geoscience Union (EGU) 2015 General Assembly, a special issue in the Natural Hazards and Earth System Sciences (NHESS) and Hydrology and Earth System Sciences (HESS) journals entitled "Effective Science Communication and Education in Hydrology and Natural Hazards" was commissioned (see e.g. Gires et al., 2016). The objective of this special issue was to bring together contributions from a broad range of disciplines across both hydrology and natural hazards in relation to best practices in effective science communication and education. Contributions were solicited that specifically addressed these issues, and which had clear objectives and research methodologies. Case studies and other experiences were also welcomed as long as they were rigorously presented and evaluated. This special issue consisted of 13 peer reviewed papers, and the resulting metrics demonstrate a good reception for these articles amongst the geoscience community, with all articles receiving wide dissemination and citation. For example, to date "Using video games for volcanic hazard education and communication: an assessment of the method and 
preliminary results" by Mani et al. (2016) has been viewed and downloaded over 2500 times. The average number of views for the papers in this special issue is currently also over 1400 at the time of writing this article (June 2018), and such a well-received special issue clearly demonstrated the wide demand for high-quality research articles in the field of geoscience communication. Therefore, the aim of $G C$ is to provide a more inclusive platform across all of the geosciences, rather than just those specific areas that are covered by HESS and NHESS.

At this point it is worth giving a definition of what we mean by the term "geoscience communication" since it is a relatively new field. Against a backdrop of growing geoenvironmental concerns, a critical challenge for scientists is how best to communicate to the wider public sphere a complex body of knowledge. Many scientists would question our current ability to meet this challenge, highlighting the apparent inadequate uptake of their expert knowledge among policy makers and other stakeholders to inform wise environmental-decision making (Kirchhoff et al., 2013). To address this, geoscientists are being encouraged to more effectively convey their technical expertise to non-technical audiences. The result is an increasing prominence of more effective communication within higher education and research organisations, as manifest in the rise of training courses for early-career scientists. The assumption underpinning much of this is that if technical information could be communicated "better", people would make choices more consistent with the science. Yet, over the last decade or so, this long-enduring and widely held view - that a deficiency of information and technical understanding lies at the root of why people do not accept scientific claims or change their behaviour in line with scientific guidance - has been called into question (see e.g. Burns et al., 2003; Bubela et al., 2009). As a recent state-ofthe-art review of effective science communication highlights (National Academies of Sciences and Medicine, 2017, p. 3),

The research on science communication, however, shows that audiences may already understand what scientists know but, for diverse reasons, do not agree or act consistently with that science. People rarely make decisions based only on scientific information: they typically also take into account their own goals and needs, knowledge and skills, and values and beliefs.

Effective communication is increasingly regarded not as one-way transfers of knowledge to the public sphere, but rather as two-way dialogues with people about the scientific matters which concern them (Stewart and Lewis, 2017). This dialogic approach has opened up an exciting range of innovative communication approaches within the geosciences which, in addition to drawing on specialised knowledge and experience from the humanities and social sciences (Lubchenco, 1998; Pidgeon and Fischhoff, 2011; Moser and
Dilling, 2011), also embraces the creative arts and philosophy and religion (Nisbet et al., 2010).

The resulting landscape of science communication is becoming ever more broad and diverse as research organisations and funding agencies encourage scientists to engage the public ever more imaginatively in their work, address their collective concerns, and even have them participate in the scientific process themselves. Scientists are expected to converse with diverse audiences - for example, science users and decision makers, the wider scientific community, public organisations, and individual citizens - in ways tailored for each audience. Much geoscience communication still rests on traditional journalistic norms of effective communication (Stewart and Nield, 2013), framing (Nisbet, 2009), storytelling (Dahlstrom, 2014), language (Somerville, 2011), and visualisation (Wang et al., 2018), but fresh ways to connect with mass popular culture through emergent digital communication channels open up exciting possibilities (Schäfer, 2012).

Geoscience communications are thus scientific activities at multiple levels that aim at increasing attention to and public discussion of geoscientific results. Thereby they cover a wide variety of initiatives, from science fairs and geotourism (see e.g. Hose, 2006) to policy briefings and science comedy. For example, we as scientists might communicate our own scientific achievements on personal or institutional websites, or the latest insights to public partners in transdisciplinary projects, or on the broadest level to news agencies about knowledge and results of high importance to mankind as such, like the spread of diseases or global warming. Some would also consider traditional geoscience journals a form of geoscientific communication, and it is our aim to embrace as much of this diversity as possible. The multifaceted nature of the wider field of science communication itself is illustrated by the many terms that are used in the field, such as widening participation, knowledge exchange or transfer, outreach, public engagement, and public benefit - all of which, including also science education, we gather here under the umbrella term of science communication (Illingworth et al., 2015). Furthermore, the geosciences cover a broad range of disciplines which, like science communication too, often depend on the research funding body, research institute, geoscientist, or cycle of the moon. Given that $G C$ belongs to the European Geosciences Union suite of scientific journals, we define the geosciences as encompassing all studies of the Earth and its environment and of the solar system in general, as covered by the EGU's 22 scientific divisions, but are also not limited just to these. We have deliberately chosen our definitions of "science communication" and the "geosciences" to be as broad and inclusive as possible, so that $G C$ covers any scholarly research which considers science communication initiatives, or the role of science communication, within the geosciences.

To summarise, geoscience communication has now become - to different extents - one of the everyday duties 
of many geoscientists. This effort for increased and (hopefully) more successful geoscience communication is especially important since nowadays science seems to be under increased public scrutiny or is even openly distrusted. Or, as Dyer (2018) has put it:

Science is increasingly facing problems with its ability to communicate ideas publicly, a problem that politicians [...] are able to circumvent with moves towards populism.

If we do not put more emphasis on how to successfully communicate geoscience, the underlying research might be as good as it always was but would ultimately still be on the losing end in the twenty-first century.

The core purpose of $G C$ is thus 2-fold.

1. To provide wider and more formal recognition for existing and future geoscience communication initiatives. A lot of great science communication work is usually performed on a voluntary basis and with little formal academic reward or recognition, so giving people the opportunity to publish their experiences and work in this area in venues that are traditionally recognised is one way to help address this problem. With the advent of Science 2.0 (an approach to science for which information-sharing and collaboration are made possible by social network technologies, and in which effective science communication plays a vital role), this is particularly important (see e.g. Peters et al., 2014).

2. In providing a platform for these initiatives, $G C$ also aims to better formalise the discipline of geoscience communication. Whilst many such initiatives are carried out with good intentions, they sometimes lack the academic rigour and longitudinal evaluation that would be expected of geoscientific research published through formal channels. In order to address these issues, and for the research that is published in $G C$ to be thoroughly robust, it may be necessary for the authors to incorporate aspects of social science, behavioural science, and science communication theory into their research.

While other science communication and public engagement journals do exist, they are often directly geared towards a social science or media studies audience, and as such many physical scientists might feel unqualified or unmotivated to publish in them (Illingworth and Prokop, 2017). However, these journals provide excellent examples of the type of research that $G C$ aims to publish: methodological, rigorous, and fully engaged with the scientific process. Where $G C$ differs from these other journals is that, as well as having a diverse team of Associate Editors to support this process, we will also have a bank of interdisciplinary researchers who can connect with the geoscientists, thereby helping them to improve their manuscript, as well as through formal peer review. This interdisciplinary and collaborative approach is unique at the journal level. Furthermore, this service will also be offered prior to manuscript submission, if requested. By supporting geoscientists in the implementation, delivery, and evaluation of their geoscience communication initiatives we, as a community, will be able to achieve the dual aims of this journal: providing a supportive platform and recognition for geoscience communication, whilst helping to better formalise it as an academic discipline.

\section{Which topics does GC cover?}

As stated above, the journal intends to embrace as much of the diversity of geoscience communication as possible, giving a forum for scientifically rigorous communication strategies in five key subject areas. As an author, you will have to choose one of these keywords so that your manuscript is assigned to an Associate Editor with expertise in one of these fields.

\section{- Geoscience education}

Geoscience education is pedagogical and andragogical research, which takes place in either a formal or informal environment. Articles can be theoretical or practical in nature. For example, manuscripts on innovative geoscience curricula development, programmes of advanced training of teachers in the geosciences, theories of geoscience instruction and learning, and reviews of the latest trends in geoscience education can be assigned to this subject area. Furthermore, social, political, and epistemological learning and teaching contexts can be addressed here.

\section{- Geoscience engagement}

In this subject area falls any research which considers engaging the general public. In the broadest sense it thus encompasses all strategies that deal with the interaction of geoscientists with non-geoscientists, or the general public utilising blogs, YouTube, Facebook, Twitter, etc., as well as offline venues including school visits and public festivals and talks. Of special interest might be studies that address the relationship between geoscientific knowledge and power, and the role of social media for this relationship.

\section{- Geoscience policy}

Geoscience policy asks how, which, and why geoscientific endeavours are funded, and how geosciences are politically (as well as economically and socially) promoted and which networks are in play - the interplay between geoscience for policy and policy for geoscience. Manuscripts that analyse supporting and hindering factors for successful geoscience policies, or articles focusing on improving and developing conceptual or empirical models of knowledge production and dissemination, are examples for this subject area. 
- History and philosophy of geosciences

Articles assigned to this subject area ask, for example, for the former and current foundations of geosciences, and which methods are and have been used, or discuss the implications of geoscientific results. They also might seek answers to the question of what qualifies as geoscientific theory and research for which reasons.

\section{- Open geoscience}

How can geoscience be made more easily accessible for the wider public, and how can public awareness of, and engagement with, geoscientific results be increased? These questions are at the core of studies in the field of open geoscience. Instead of understanding it rather strictly as diverse open-access strategies that rather focus on successful dissemination of geoscientific results, $G C$ also welcomes studies on public participation in the scientific process, as e.g. in citizen science projects, as well as broader issues in open scholarship such as research evaluation and data sharing.

\section{What are the ethics of Geoscience Communication?}

High ethical standards at $G C$ are crucial to ensure the high quality of scientific articles that we publish, to ensure both the credibility of scientific findings and that authors (and all other engaged parties) receive appropriate credit for their work. At $G C$, we adhere to the typical ethical standards expected from the research community during scholarly publishing. We follow the principles of transparency and best practice outlined by the Committee on Publication Ethics (COPE), and as such we are committed to full transparency in terms of the governance structure of the journal, the peer review process, copyright and licensing, and what authors and readers can expect from the journal on behalf of the publisher, Copernicus.

Copernicus Publications has several existing policies that help us to meet these high ethical standards. These guidelines can be viewed in the general terms, the general obligations for authors, the general obligations for editors, our publication policy, and the general obligations for referees (all of which are available on the $G C$ website). Furthermore, we fully adopt the joint AGU-EGU code of conduct for rigour, respect, and responsibility, which is embedded within all of our professional activities.

We strongly recommend that submitting authors deposit any data that correspond to journal articles in reliable data repositories, assign digital object identifiers, and properly cite any data sets as individual contributions, in accordance with our data policy. Furthermore, we encourage authors to share their research as early as they possibly can in preprint servers such as EarthArXiv, to help maximise the dissemination of their work. All articles published by $G C$ will have a Creative Commons CC BY 4.0 license assigned to them, which ensures that authors retain all of the rights to their work, while encouraging sharing and adaptation, as long as their works are appropriately cited.

The Editorial Board is fully aware of the numerous ongoing transformations happening in the world of scholarly publishing. It is our priority to remain aware of these, and make sure that the journal is continuously acting in the best interests of the authors and the wider geoscience community, while upholding the strongest ethical and scientific standards possible.

\section{What should a manuscript look like?}

In order to help you in your research design, evaluation, and manuscript preparation we have put together a list for prospective authors. This list is not exhaustive, but it should act as a useful checklist when preparing your manuscript for submission to $G C$. However, in order for this list to be of the greatest benefit, we suggest that you first consult it when designing your science communication initiative, and then refer to it throughout the delivery and development of your research, as doing so will ensure that you have everything you need when preparing your manuscript. For most of the items on this list we have also tried to provide a suitable reference that either illustrates the point or provides an example of best practice.

1. All research articles should include qualitative and/or quantitative evidence, and not solely anecdotal reporting. For example, a research paper that aims to report on the effectiveness of a public engagement initiative that communicates volcano risks through the use of mime should have qualitative or quantitative evidence that supports the effectiveness of the initiative and demonstrates how impact has been achieved. A recent publication that utilised such an approach was Gravina et al. (2017), who investigated how social media can be used to communicate important natural hazard information, and which included a thorough quantitative analysis of the reach and impact of a variety of social media channels.

2. All research articles should include an explicitly marked section that considers the ethics of the investigation and should also demonstrate how the research has received ethical clearance from their research institute or professional body. If this is not possible, then a clear rationale should be given for any extenuating circumstances, ideally in the cover letter to the editor upon submission of the manuscript. Furthermore, if institutional ethical approval is not possible (e.g. if you are an independent researcher), then the ethical guidelines for a country or governing body should be adhered to: for example, the British Educational Research Association (BERA) pro- 
vides ethical guidelines for educational research (see e.g. Flewitt, 2005).

3. Any research articles that involve an interdisciplinary approach should demonstrate how they have integrated the practitioners from the different disciplines (e.g. artists, poets, social scientists) at the very start of the process, and not just tacked them on at the end as a ribbon. A recent publication that serves as an exemplar for such integrated collaboration is Stiller-Reeve and Naznin (2017), who worked with local communities in Bangladesh, using art to design citizen science projects in close dialogue with the project's climate scientists and artists.

4. We encourage authors to make use of online supplements to share materials (e.g. survey items, slide decks, videos, summaries for policymakers, or any other supporting information). If supplements are not included and the manuscript includes links to materials archived online, then only URLs with stable long-term storage should be used. Kirchner et al. (2018) provide a great example of how this can be done effectively, as in addition to reporting on the development of an ice-sheet model for use in introductory Earth science courses, they also provide detailed guidelines for how to adapt and deliver the discussed learning activities in a classroom environment.

5. Any limitations of the study, including sources of bias, should be clearly discussed. These might include limitations for when, where, and with whom the innovation is likely to work, or limitations of the instruments or metrics used in the evaluation. A recent publication that demonstrated how a discussion of limitations is extremely useful for future researchers is Arnal et al. (2016), which describes in great detail the limitations of their risk-based decision-making game for flood forecasting, and makes clear how future researchers can build on what they have achieved. We feel that including such self-reflection is part of good scientific practice, and therefore strongly encourage it.

6. Footnotes should be avoided, as they tend to disrupt the flow of the text. If absolutely necessary, they should be numbered consecutively. Footnotes to tables should be marked by lowercase letters. Similarly, hyperlinks to URLs should also be avoided if a secondary source such as a journal article or report can instead be referenced. If URLs are used, then the reference should always include an access date.

7. We are committed to the inclusion and contributions from academics, practitioners, and community partners regardless of demographic, ethnographic, or psychographic background (e.g. race, age, culture, ability, ethnicity or nationality, gender identity and expression, sexual orientation, marital status, religious affiliation, and socioeconomic status). We affirm the worth and dignity of every member of the research community and strongly believe that the affirmation of this diversity is of both intrinsic and instrumental value. Moreover, we ascertain that making visible diverse contributions leads to richer debates and knowledge in the area of research and beyond. The Equality Act (2010) provides a legal framework to protect the rights of individuals and advance equality of opportunity for all. Geoscience Communication stands behind everything that is written in that act and will actively work to promote diversity and persecute prejudice or bullying of any sort.

8. We expect all of our authors to fully engage with the peer review process, and not just to treat it as a box-ticking exercise. We recognise that there are many things that people find perplexing about many aspects of peer review, but these are mainly centred around recognition. At present, we feel it still provides the optimal way to validate and ensure scientific integrity. $G C$ utilises a collaborative two-stage peer review process, with Geoscience Communication Discussions (GCD) offering an online and open platform for public peer review, prior to a final editorial decision. Here, the objective is for civil, critical discussion to improve manuscripts for eventual publication, and not to find reasons why they should be rejected. We would strongly encourage authors and readers to engage in this space as a community, and to use it as a learning tool that can help to improve future manuscripts. Further evidence for the benefits of the peer review system, along with an open discussion of its merits and alternatives, is given by e.g. Ware (2008) and Tennant et al. (2017).

9. We expect that the majority of the publications in $G C$ will be scholarly research articles. If you are considering a review (systematic or otherwise) article, then please contact a member of the editorial board before beginning work on the manuscript. Review articles can be extremely useful publications for the wider community, and do not necessarily have to be written by a "known name" in the field. However, we would expect a thorough justification for why this review article needs to be published, and why you the proposed author(s) are the ideal person(s) to do so. An example of a genuinely excellent review article in the field of science communication is Weigold (2001), which provides an overview of science communication, and contextualises the literature to suggest ways of improving the practice of science communication, as well as an agenda for future research.

10. Geoscience Communication presents an opportunity for special issues, which can represent an effective way of collating a corpus of work. However, they can also turn 
into puddles of nepotistic quicksand. Therefore, while we encourage the proposal of special issues, we will be limiting them in number for the first few years of the journals. As with any review articles, we would expect a thorough justification from the proposed authors, outlining why a special issue merits such attention, and why they are suitable candidates to be guest editors for the process.

We hope that the above list serves as a useful aide or memoire for when you are designing your geoscience communication initiatives, evaluating your findings, and preparing your manuscripts. We hope that this also inspires you to discover new methods of communicating geoscientific research, or, for geoscientists, at least think about wider issues and the importance of scientific communication. However, we would like to remind you that all of the editorial team are human beings, and that we are very happy to provide any help or assistance that you might have during any stage of your research or submission. Our inboxes are always open, and it is far better to ask for answers to any niggling questions that you may have before you submit your manuscript (or even better, when you are planning your initiative or research project), than halfway through the revision process.

\section{Final thoughts}

We hope that this editorial has served as a useful introduction to the scope and need for $G C$, and that in reading it you have a better idea of the manuscripts that we are looking for, and the assistance and help that we can give during the peer review process. The most important thing to remember is that this is not our journal though, it is yours. And so, as well as any questions and inquiries that you may have (and which are not covered by this editorial), we would genuinely love to hear any suggestions that you might have for us to improve the journal. Do we need video abstracts? Should we be embracing Snapchat? Is there a key area of geoscience communication that we are missing?

Likewise, if you would like to be an Associate Editor or a reviewer for the journal and think that you have the skills to do so, please get in touch. Even if you do not have the skills now but want to find out about how to get them, then please get in touch. As the title of this editorial puts it, for us peer review and publication are all about building bridges not walls, and it is only by working together in a collaborative and supportive manner that we can better hope to create research that is diverse, important, and beneficial to the whole of society.

Data availability. No primary data sets were used in producing this article.
Author contributions. SI, IS, JT, and KvE all designed and cowrote the paper in equal amounts.

Competing interests. The authors declare that they have no conflict of interest.

Acknowledgements. We would like to thank everyone at Copernicus Publications and the European Geosciences Union for their help in the development of Geoscience Communication. In particular we would like to thank Hubert Savenije and Martin Rasmussen, both of whom have been instrumental in providing the support that was needed to launch this journal. We would also like to thank all of the geoscientists who conduct such amazing research in the field of geoscience communication, without whom this journal would not exist.

\section{References}

Arnal, L., Ramos, M.-H., Coughlan de Perez, E., Cloke, H. L., Stephens, E., Wetterhall, F., van Andel, S. J., and Pappenberger, F.: Willingness-to-pay for a probabilistic flood forecast: a riskbased decision-making game, Hydrol. Earth Syst. Sci., 20, 3109 3128, https://doi.org/10.5194/hess-20-3109-2016, 2016.

Bubela, T., Nisbet, M. C., Borchelt, R., Brunger, F., Critchley, C., Einsiedel, E., Geller, G., Gupta, A., Hampel, J., and Hyde-Lay, R.: Science communication reconsidered, Nat. Biotechnol., 27, 514-518, 2009.

Burns, T. W., O'Connor, D. J., and Stocklmayer, S. M.: Science communication: a contemporary definition, Public Underst. Sci., 12, 183-202, 2003.

Dahlstrom, M. F.: Using narratives and storytelling to communicate science with nonexpert audiences, P. Natl. Acad. Sci. USA, 111, 13614-13620, 2014.

Dyer, H.: I watched an entire Flat Earth Convention for my research - here's what I learnt. The conversation, available at: http://theconversation.com/i-watched-an-entire-flat-earthconvention-for-my-research-heres-what-i-learnt-95887 (last access: 1 June 2018), 2018.

Equality Act: Equality Act, 2010, c. 15, UK National Archives website, available at: http://www.legislation.gov.uk/ukpga/2010/15/ contents (last access: 6 June 2018), 2010.

Flewitt, R.: Conducting research with young children: Some ethical considerations, Early Child Development and Care, 175, 553$565,2005$.

Gires, A., Muller, C. L., le Gueut, M.-A., and Schertzer, D.: Making rainfall features fun: scientific activities for teaching children aged 5-12 years, Hydrol. Earth Syst. Sci., 20, 1751-1763, https://doi.org/10.5194/hess-20-1751-2016, 2016.

Gravina, T., Muselli, M., Ligrone, R., and Rutigliano, F. A.: SUstaiNability: a science communication website on environmental research, Nat. Hazards Earth Syst. Sci., 17, 1437-1446, https://doi.org/10.5194/nhess-17-1437-2017, 2017.

Hose, T. A.: Geotourism and interpretation, in: Geotourism, edited by: Dowling, R. and Newsome, D., Elsevier, London, 221-241, 2006. 
Illingworth, S. and Prokop, A.: Science communication in the field of fundamental biomedical research, Semin. Cell Dev. Biol., Elsevier, 70, 1-9, 2017.

Illingworth, S., Redfern, J., Millington, S. and Gray, S.: What's in a Name? Exploring the Nomenclature of Science Communication in the UK, version 2, 4: 409, https://doi.org/10.12688/f1000research.6858.2, 2015.

Kirchhoff, C. J., Lemos, M. C., and Dessai, S.: Actionable knowledge for environmental decision making: broadening the usability of climate science, Annu. Rev. Env. Resour., 38, 393-414, 2013.

Kirchner, N., Van Dongen, E., Gowan, E. J., Pattyn, F., Noormets, R., Jakobsson, M., and Ingólfsson, Ó.: GRANTSISM: An Excel $^{\mathrm{TM}}$ ice sheet model for use in introductory Earth science courses, Journal of Geoscience Education, 66, 109-120, 2018.

Lubchenco, J.: Entering the century of the environment: a new social contract for science, Science, 279, 491-497, 1998.

Mani, L., Cole, P. D., and Stewart, I.: Using video games for volcanic hazard education and communication: an assessment of the method and preliminary results, Nat. Hazards Earth Syst. Sci., 16, 1673-1689, https://doi.org/10.5194/nhess16-1673-2016, 2016.

Moser, S. C. and Dilling, L.: Communicating climate change: closing the science-action gap, The Oxford Handbook of Climate Change and Society, 161-174, Oxford University Press, Oxford, UK, 2011.

National Academies of Sciences and Medicine: Communicating science effectively: A research agenda, National Academies Press, Washington DC, USA, 2017.

Nisbet, M. C.: Framing science: A new paradigm in public engagement, in: Understanding science: New agendas in science communication, edited by: Kahlor L. and Stout P., 40-67, Taylor \& Francis, New York, USA, 2009.

Nisbet, M. C., Hixon, M. A., Moore, K. D., and Nelson, M.: Four cultures: New synergies for engaging society on climate change, Front. Ecol. Environ., 8, 329-331, 2010.
Peters, H. P., Dunwoody, S., Allgaier, J., Lo, Y. Y., and Brossard, D.: Public communication of science 2.0: Is the communication of science via the "new media" online a genuine transformation or old wine in new bottles?, EMBO reports, e201438979, EMBO Press, Heidelberg, Germany, 2014.

Pidgeon, N. and Fischhoff, B.: The role of social and decision sciences in communicating uncertain climate risks, Nature Climate Change, 1, 35-41, 2011.

Schäfer, M. S.: Online communication on climate change and climate politics: a literature review, WIRES Clim. Change, 3, 527543, 2012.

Somerville, R. C.: Communicating the science of climate change, Phys. Today, 64, 48-53, 2011.

Stewart, I. S. and Nield, T.: Earth stories: context and narrative in the communication of popular geoscience, Proceedings of the Geologists' Association, 124, 699-712, 2013.

Stewart, I. S. and Lewis, D.: Communicating contested geoscience to the public: Moving from "matters of fact" to "matters of concern”, Earth-Sci. Rev., 174, 122-133, 2017.

Stiller-Reeve, M. and Naznin, Z.: A Climate for Art: Enhancing Scientist-Citizen Collaboration In Bangladesh, B. Am. Meteorol Soc., 99, 491-497, https://doi.org/10.1175/BAMS-D-16-0044.1, 2017.

Tennant, J. P., Dugan, J. M., Graziotin, D., Jacques, D. C., Waldner, F., Mietchen, D., Elkhatib, Y., Collister, L. B., Pikas, C. K., and Crick, T.: A multi-disciplinary perspective on emergent and future innovations in peer review, version 3, F1000Research 2017, 6, 1151, https://doi.org/10.12688/f1000research.12037.3, 2017.

Wang, S., Corner, A., Chapman, D., and Markowitz, E.: Public engagement with climate imagery in a changing digital landscape, WIRES Clim. Change, 9, e509, https://doi.org/10.1002/wcc.509, 2018.

Ware, M.: Peer review: benefits, perceptions and alternatives, Publishing Research Consortium, 4, 1-20, 2008.

Weigold, M. F.: Communicating science: A review of the literature, Sci. Commun., 23, 164-193, 2001. 